\title{
Endoscopic third ventriculostomy for VP shunt malfunction during the third trimester of pregnancy: illustrative case
}

\author{
Ahmad K. Alhaj, MD, ${ }^{1}$ Tariq Al-Saadi, MD, ${ }^{2}$ Marie-Noëlle Hébert-Blouin, MD, FRCSC, ${ }^{2}$ Kevin Petrecca, MD, PhD, FRCSC, ${ }^{2}$ and \\ Roy W. R. Dudley, MD, PhD, FRCSC ${ }^{3}$
}

${ }^{1}$ Department of Neurosurgery, Ibn Sina Hospital, Ministry of Health, Kuwait City, Kuwait; ${ }^{2}$ Department of Neurology and Neurosurgery, Montreal Neurological Institute-Hospital, McGill University, Montreal, Quebec, Canada; and '3ivision of Neurosurgery, Department of Pediatric Surgery, McGill University, Montreal, Quebec, Canada

BACKGROUND Endoscopic third ventriculostomy (ETV) is a successful procedure for treating noncommunicating hydrocephalus as an alternative to initial ventriculoperitoneal (VP) shunt placement and as a salvage procedure when a VP shunt fails. Physiological changes of pregnancy can lead to VP shunt failure and complicate the management of shunt malfunction, particularly in the third trimester.

OBSERVATIONS The authors present a case in which an ETV was successfully used in the third trimester (31 weeks of gestation) of pregnancy for acute hydrocephalus due to VP shunt malfunction, and the patient went on to deliver a healthy baby at term; the patient remained well in the long-term follow-up. An English-language PubMed literature review revealed four cases of VP shunt failure successfully treated with an ETV in the first or second trimester but no such reports in the third trimester of pregnancy.

LESSONS ETV appears to be a safe and effective alternative to VP shunt replacement in the late prenatal period of pregnancy.

https://thejns.org/doi/abs/10.3171/CASE2054

KEYWORDS endoscopic third ventriculostomy; ETV; pregnancy; ventriculoperitoneal shunt

Endoscopic third ventriculostomy (ETV) is an effective treatment for noncommunicating hydrocephalus. ${ }^{1-3}$ As predicted by the ETV Success Score (ETVSS), its effectiveness depends on patient age, the pathology causing hydrocephalus, and whether the patient had a previous ventriculoperitoneal (VP) shunt. Success rates reach $90 \%$ in well-selected candidates. ${ }^{4}$ ETV has also been found to be a valuable salvage option for VP shunt malfunction, with success rates of $60 \%-80 \% .^{5-10}$

In VP shunt-dependent women, the physiological changes of pregnancy may impair shunt function, mostly due to uterus enlargement and increased intraabdominal pressure (IAP). ${ }^{11-16}$ VP shunt revision surgery in the late prenatal period presents unique challenges, particularly regarding access to the peritoneal space.

Here, we describe a case in which an ETV was performed for shunt malfunction in the third trimester. We also present a PubMed review of the English-language literature for similar cases.

\section{Illustrative Case}

A 36-year-old, 31-weeks-pregnant woman presented with headache, confusion, and unsteady gait. At 9 years old, she had a VP shunt inserted (Fig. 1A) for noncommunicating hydrocephalus caused by a low-grade tectal glioma (Fig. 1B) and never needed a shunt revision. On this presentation, she was awake and alert but disoriented with upward gaze palsy and vertical nystagmus. An urgent head computed tomography (CT) (Fig. 1C) revealed acute triventricular hydrocephalus with transependymal edema. Shunt series radiographs (Fig. 1D-F) showed no disconnection. Initially, there was a plan to attempt exploration and shunt revision, but there was concern that the malfunction was due to pregnancy-related increased IAP. If any distal catheter revision surgery would have been required at this stage, it would have been more challenging and would have increased the risk to the fetus and mother. Therefore, the decision was made to proceed with an ETV to avoid a shunt revision altogether. Her age and primary

ABBREVIATIONS CSF = cerebrospinal fluid; CT = computed tomography; $E T V=$ endoscopic third ventriculostomy; $E T V S S=E T V$ Success Score; $E$ VD = external ventricular drain; IAP = intraabdominal pressure; ICP = intracranial pressure; MRI = magnetic resonance imaging; VP = ventriculoperitoneal.

INCLUDE WHEN CITING Published January 11, 2021; DOI: 10.3171/CASE2054.

SUBMITTED October 6, 2020. ACCEPTED October 28, 2020.

(C) 2021 The authors, CC BY-NC-ND 4.0 (http://creativecommons.org/licenses/by-nc-nd/4.0/) 

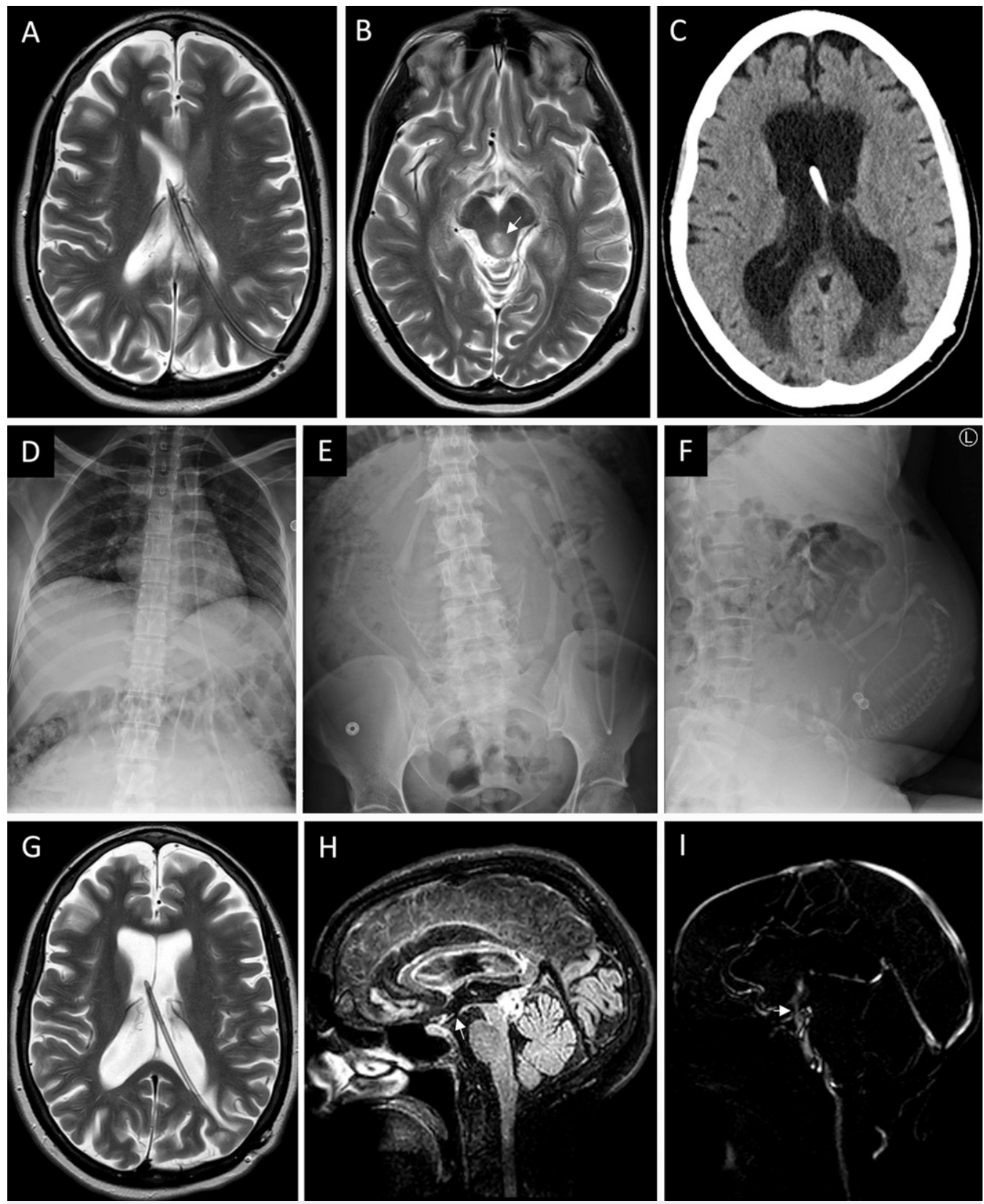

FIG. 1. Axial T2 MRI demonstrating shunted hydrocephalus with small ventricles at baseline (A) and tectal glioma (arrow) compressing the cerebral aqueduct as the primary cause of her hydrocephalus (B). Plain head CT at presentation in the third trimester of pregnancy showing significantly dilated ventricles and transependymal edema (C). Shunt series radiographs demonstrating no kinks or disconnections of the distal VP shunt system in the chest (D) or abdomen on anterior-posterior (E) and lateral views $(\mathbf{F})$ (note the fetal skeleton within the enlarged gravid uterus silhouette $[\mathbf{E}, \mathbf{F}])$. Axial T2 MRI 10 weeks after the ETV was performed $(\mathbf{G})$, when the patient was asymptomatic, demonstrating that the ventricles had decreased in size but had not returned to their previous shunted baseline size. Sagittal fluid-attenuated inversion recovery MRI showing the ventriculostomy (arrow) in the floor of the third ventricle (H). MRI CSF flow study demonstrating flow signal (arrow) at the ventriculostomy site (I).

obstructive pathology were in support of this decision because she had $>80 \%$ chance of ETV success based on the ETVSS. Ventriculostomy was successfully achieved without complications; the VP shunt was not removed in case the ETV failed in the future. The next day she was alert, fully oriented, and mobilizing without any significant headache, and she was discharged home. Four weeks later she gave birth to a healthy girl by vaginal delivery. Six weeks after giving birth she underwent magnetic resonance imaging (MRI) with a cerebrospinal fluid (CSF) flow study, which demonstrated decreased ventricle size (Fig. 1G), patency (Fig. 1H), and flow (Fig. 1I) at the ventriculostomy. She remained well six months after the ETV and has not required any other surgical interventions. 


\section{Discussion}

We searched PubMed for English-language reports of VP shunt malfunction in the late prenatal period managed using an ETV (search not confined to specific dates). We used combinations of the following search terms: endoscopic third ventriculostomy, ETV, third ventriculostomy, pregnancy, prenatal, shunt malfunction, shunt infection, and shunt failure. This search revealed two publications reporting four cases of VP shunt malfunction treated with an ETV during pregnancy (Table 1). Riffaud et al. ${ }^{3}$ reported three pregnant women who underwent uncomplicated conversion to an ETV, uneventful vaginal deliveries of healthy babies, and remained well at 2-3 years' follow-up. Yoshida et al. ${ }^{17}$ described a patient who was also successfully treated with an ETV and delivered a healthy baby vaginally. Unlike our third trimester case, three of these previously reported cases presented in the second trimester and one in the first trimester. To the best of our knowledge, the new case we present here is the first report in the literature of the treatment of VP shunt failure by an ETV in the third trimester.

\section{Observations}

Little has been written about the use of an ETV in the management of women with VP shunt failure during pregnancy. More than threequarters of women with VP shunts have neurological complications during pregnancy, two-thirds with symptoms of increased intracranial pressure (ICP). ${ }^{11}$ Physiological changes of late pregnancy include the enlarged gravid uterus and increased IAP, not to mention the live fetus existing in an area that may require surgical manipulation during VP shunt revision. As illustrated, VP shunt failure in the late prenatal period presents a unique set of challenges in the neurosurgical management of such patients.

The normal IAP for nonobese adult women ranges from subatmospheric to $7 \mathrm{~mm} \mathrm{Hg}$, and during the late third trimester of pregnancy this can double to $14 \pm 2.6 \mathrm{~mm} \mathrm{Hg.}{ }^{18}$ Most VP shunt valves are pressure-controlled, differential pressure valves meaning that the valve "opens" when the ICP is greater than the IAP by a fixed amount, based on the setting of the valve. For example, if a healthy, nonpregnant women had an IAP of $5 \mathrm{~mm} \mathrm{Hg}$ and a medium pressure valve with an opening differential pressure of $8 \mathrm{~mm} \mathrm{Hg}$, her shunt would drain whenever the ICP was $>13 \mathrm{~mm} \mathrm{Hg}(5 \mathrm{~mm} \mathrm{Hg}+8 \mathrm{~mm} \mathrm{Hg})$. However, if in the late stages of pregnancy her IAP increased to $14 \mathrm{~mm} \mathrm{Hg}$, her ICP would have to be $>22 \mathrm{~mm} \mathrm{Hg}(14 \mathrm{~mm} \mathrm{Hg}+8 \mathrm{~mm} \mathrm{Hg}$ ) for the shunt to drain. She would likely have ventricular enlargement and symptoms of raised ICP. Several published cases support this proposed mechanism. Sasagawa et al. ${ }^{19}$ reported a case in which a VP shunt valve was repeatedly pumped, allowing the expectant mother's symptoms to resolve while waiting for the baby to be delivered. Murakami et al. ${ }^{20}$ reported successfully treating a pregnancy-related VP shunt failure by converting to a ventriculoatrial shunt. There have even been reports of having to perform a cesarean section to get the shunt working again. ${ }^{16}$ Of course, it may not always be a distal malfunction due to increased IAP that is causing the problem; it could be the proximal catheter or valve that is not working properly. In our case, we were concerned that the shunt was failing due to increased IAP and decided to address this by performing an ETV. However, we left the previous shunt in situ in case the ETV failed. The fact that the ventricles remained larger 10 weeks after the ETV than they were when her shunt was working well (in an asymptomatic patient), despite what we can assume was a return to baseline IAP, suggests that the shunt was still not working, and it was the ventriculostomy that was successfully treating the hydrocephalus. ${ }^{21}$ This MRI finding was somewhat surprising in light of our hypothesis regarding increased IAP being the cause of the shunt malfunction. Either our hypothesis was wrong or the cessation of flow due to increased IAP (and no flow from the distal catheter tip in the abdomen) allowed a tissue clot to form within the tube or allowed adhesions to form at the tip, such that once the IAP returned to normal the catheter was still blocked. Another possibility, of course, is always that some bleeding during the ETV procedure actually blocked the shunt, but there was no significant bleeding during the ETV procedure in this case.

\section{Lessons}

Our case supports the use of an ETV to treat VP shunt malfunction in the late prenatal period. However, this may not always be a suitable or safe first option. In an emergency situation (e.g., comatose state), it is necessary to rapidly obtain clearly functional CSF diversion. An attempt can be made to perform a high-volume valve tap while waiting to go to the operating room, but either the shunt should be externalized (if flowing well) or a confirmed functioning external ventricular drain (EVD) must be left in place. If an ETV is performed in the same setting, a functioning EVD should still be left in place in case the ETV fails. If the

TABLE 1. Cases of successful ETV procedures for the management of VP shunt malfunction during pregnancy

\begin{tabular}{|c|c|c|c|c|c|c|}
\hline Authors \& Year & $\begin{array}{l}\text { No. of } \\
\text { Cases }\end{array}$ & $\mathrm{Age}^{*}, \mathrm{GA} \dagger$ & Presentation & $\begin{array}{c}\text { Primary Pathology for } \\
\text { Hydrocephalus }\end{array}$ & $\begin{array}{l}\text { Time of First } \\
\text { VP Shunt }\end{array}$ & $\begin{array}{l}\text { Mode of } \\
\text { Delivery }\end{array}$ \\
\hline & & 33 yrs, 20 wks & $\begin{array}{l}\text { Headache, vomiting, visual } \\
\text { disturbance }\end{array}$ & Midbrain calcified tectal lesion & Since 12 yrs old & NVD \\
\hline \multirow[t]{2}{*}{ Riffaud et al., $2006^{3}$} & 3 & $26 \mathrm{yrs}, 15 \mathrm{wks}$ & Headache \& visual disturbance & $\begin{array}{l}\text { Primary congenital aqueduct } \\
\text { stenosis }\end{array}$ & Since 6 mos old & NVD \\
\hline & & $27 \mathrm{yrs}, 8 \mathrm{wks}$ & Headache & $\begin{array}{l}\text { Unknown midbrain tectal } \\
\text { lesion }\end{array}$ & Since 25 yrs old & NVD \\
\hline Yoshida et al., $2007^{17}$ & 1 & 33 yrs, 24 wks & $\begin{array}{c}\text { Disturbance of consciousness \& } \\
\text { dizziness }\end{array}$ & $\begin{array}{c}\text { Primary congenital aqueduct } \\
\text { stenosis }\end{array}$ & Since 17 yrs old & NVD \\
\hline Our paper & 1 & 36 yrs, 31 wks & $\begin{array}{c}\text { Headache, disturbance of } \\
\text { consciousness, \& unsteady gait }\end{array}$ & Tectal low-grade glioma & Since 9 yrs old & NVD \\
\hline
\end{tabular}

$\mathrm{GA}=$ gestational age $\mathrm{NVD}=$ normal vaginal delivery .

* Patient age.

$\dagger \mathrm{GA}$ at the time of clinical presentation of shunt failure given in weeks. 
neurosurgeon managing the case does not have sufficient ETV experience (or such experience is unavailable), again, the goal is to secure a functioning externalized shunt or EVD; an ETV can be considered when the patient is well enough. Finally, an obstetrician should be consulted for ETV, particularly if any attempt at intraabdominal surgery is considered.

In conclusion, this case report adds to the sparse literature regarding the use of an ETV to treat VP shunt malfunction in the third trimester of pregnancy. This appears to be a unique first-time report of the use of an ETV during this specific challenging prenatal period. Keeping in mind the possibility of reporting bias, in which similar unsuccessful cases might not be reported, our account suggests that an ETV is an efficacious and safe alternative to VP shunt revision during the third trimester of pregnancy in well-selected candidates.

\section{References}

1. Kahle KT, Kulkarni AV, Limbrick DD Jr, et al. Hydrocephalus in children. Lancet. 2016;387(10020):788-799.

2. Jones RF, Stening WA, Brydon M. Endoscopic third ventriculostomy. Neurosurgery. 1990;26(1):86-92.

3. Riffaud L, Ferre JC, Carsin-Nicol B, et al. Endoscopic third ventriculostomy for the treatment of obstructive hydrocephalus during pregnancy. Obstet Gynecol. 2006;108(3 Pt 2):801-804.

4. Kulkarni AV, Drake JM, Kestle JR, et al. Predicting who will benefit from endoscopic third ventriculostomy compared with shunt insertion in childhood hydrocephalus using the ETV Success Score. J Neurosurg Pediatr. 2010;6(4):310-315.

5. Spennato $P$, Ruggiero $C$, Aliberti F, et al. Third ventriculostomy in shunt malfunction. World Neurosurg. 2013;79(2 Suppl):S22.e21-S22.e26.

6. Bilginer B, Oguz KK, Akalan N. Endoscopic third ventriculostomy for malfunction in previously shunted infants. Childs Nerv Syst. 2009;25(6):683-688.

7. Boschert J, Hellwig D, Krauss JK. Endoscopic third ventriculostomy for shunt dysfunction in occlusive hydrocephalus: long-term follow up and review. J Neurosurg. 2003;98(5):1032-1039.

8. Buxton N, Macarthur D, Robertson I, et al. Neuroendoscopic third ventriculostomy for failed shunts. Surg Neurol. 2003;60(3): 201-204.

9. Cinalli G, Salazar C, Mallucci C, et al. The role of endoscopic third ventriculostomy in the management of shunt malfunction. Neurosurgery. 1998;43(6):1323-1327.

10. Hader WJ, Walker RL, Myles ST, et al. Complications of endoscopic third ventriculostomy in previously shunted patients. Neurosurgery. 2008;63(1)(suppl 1):ONS168-ONS174.

11. Wisoff JH, Kratzert KJ, Handwerker SM, et al. Pregnancy in patients with cerebrospinal fluid shunts: report of a series and review of the literature. Neurosurgery. 1991;29(6):827-831.
12. Cusimano MD, Meffe FM, Gentili F, et al. Ventriculoperitoneal shunt malfunction during pregnancy. Neurosurgery. 1990;27(6): 969-971.

13. Gast MJ, Grubb RL Jr, Strickler RC. Maternal hydrocephalus and pregnancy. Obstet Gynecol. 1983;62(3)(suppl):29s-31s.

14. Hanakita J, Suzuki T, Yamamoto Y, et al. Ventriculoperitoneal shunt malfunction during pregnancy. Case report. J Neurosurg. 1985;63(3):459-460.

15. Kleinman G, Sutherling W, Martinez $M$, et al. Malfunction of ventriculoperitoneal shunts during pregnancy. Obstet Gynecol. 1983;61(6):753-754.

16. Schiza S, Stamatakis E, Panagopoulou A, et al. Management of pregnancy and delivery of a patient with malfunctioning ventriculoperitoneal shunt. J Obstet Gynaecol. 2012;32(1):6-9.

17. Yoshida S, Minekawa R, Shimoya K, et al. Endoscopic third ventriculostomy during pregnancy. Int J Gynaecol Obstet. 2007; 99(3):249-250.

18. Staelens AS, Van Cauwelaert S, Tomsin K, et al. Intra-abdominal pressure measurements in term pregnancy and postpartum: an observational study. PLoS One. 2014;9(8):e104782.

19. Sasagawa $Y$, Sasaki T, Fuji T, et al. [Ventriculoperitoneal shunt malfunction due to pregnancy]. Article in Japanese. No Shinkei Geka. 2006;34(2):181-187.

20. Murakami M, Morine M, Iwasa T, et al. Management of maternal hydrocephalus requires replacement of ventriculoperitoneal shunt with ventriculoatrial shunt: a case report. Arch Gynecol Obstet. 2010;282(3):339-342.

21. Beni-Adani L, Siomin V, Segev Y, et al. Increasing chronic subdural hematoma after endoscopic III ventriculostomy. Childs Nerv Syst. 2000;16(7):402-405.

\section{Disclosures}

The authors report no conflict of interest concerning the materials or methods used in this study or the findings specified in this paper.

\section{Author Contributions}

Conception and design: Dudley. Acquisition of data: all authors Analysis and interpretation of data: Dudley, Petrecca. Drafting the article: Dudley, Alhaj, Al-Saadi, Petrecca. Critically revising the article: Dudley, Al-Saadi, Hébert-Blouin, Petrecca. Reviewed submitted version of manuscript: Dudley, Alhaj, Hébert-Blouin, Petrecca. Approved the final version of the manuscript on behalf of all authors: Dudley. Administrative/technical/material support: Dudley. Study supervision: Dudley.

\section{Correspondence}

Roy W. R. Dudley: McGill University, Montreal, QC, Canada. roy.dudley@mcgill.ca. 